\title{
STRUCTURAL CHARACTERIZATION OF CORROSION IN SAE 1020 STEEL EXPOSED TO URBAN, INDUSTRIAL AND RURAL ENVIRONMENTS
}

\author{
CARACTERIZAÇÃO ESTRUTURAL DE CORROSÃO \\ DE AÇO SAE 1020 EXPOSTO A AMBIENTES URBANO, \\ INDUSTRIAL E RURAL
}

\author{
José Flavio Marcelino Borges ${ }^{1}$, Andrea Paesano Júnior², Irineu Mazzaro ${ }^{3}$ \\ ${ }^{1}$ Departamento de Física, Universidade Estadual de Ponta Grossa. E-mail: < fborges@uepg.br> \\ 2 Departamento de Física, Universidade Estadual de Maringá. E-mail: < paesano@wnet.com.br> \\ ${ }^{3}$ Departamento de Física, Universidade Federal do Paraná. E-mail: < mazzaro@fisica.ufpr.br>
}

\begin{abstract}
In this study SAE 1020 steel plates were exposed to different atmospheric environments - a rural zone, an industrial area and an urban neighborhood of the same city in the south of Brazil. After exposure intervals of 60 and 120 days, samples were collected in the form of dust from the plates' surface. The products originated from steel corrosion were analyzed by X-ray diffraction and Mössbauer spectroscopy. Differences were observed in the evolution of corrosion for each environment where the samples were exposed. According to the Hiller model, the rural zone was the more aggressive environment.
\end{abstract}

Keywords: Steel. Mössbauer spectroscopy. X-ray diffraction. Atmospheric corrosion.

\section{RESUMO}

Neste trabalho, placas de aço SAE 1020 foram expostas à diferentes ambientes atmosféricos - na zona rural, em área industrial e na região urbana da mesma cidade, no estado do Paraná, sul do Brasil. Amostras do produto de corrosão superficial dos aços foram coletadas após 60 e 120 dias de exposição. Foram feitas analises através de difratometria de raios- $\mathrm{X}$ e Espectroscopia Mössbauer. Foram observadas diferenças na evolução da corrosão das amostras expostas aos diferentes ambientes. De acordo com esquema de Hiller, a zona rural apresentou um ambiente mais agressivo aos aços.

Palavras-chave: Aços. Espectroscopia Mössbauer. Difração de raios-X. Corrosão atmosférica. 


\section{INTRODUCTION}

Corrosion processes are considered to be heterogeneous chemical reactions or electrochemical reactions that usually take place at the separation surface between the metal and the corrosive environment. (TAHARA, 2005) The atmosphere is the environment to which metals are most often exposed. The composition of the atmosphere varies depending on the site, geography and season, and therefore the atmosphere is extremely complex. Consequently, atmospheric corrosion is still not completely understood, although it is the most ancient form of corrosion among those known to exist. (OH, 1999) The chemical composition of the atmosphere is quite constant, except for water steam, which follows the variations of the climate, season and site. Among other components, $\mathrm{O}_{2}$ and $\mathrm{CO}_{2}$ are important from the point of view of corrosion because the diffusion of oxygen through the film, from one interface to another, is very fast. In the case of metals covered with oxide, and depending on the oxide's properties, there might be a critical humidity value at which the corrosion rate increases. Besides steam, other water sources from the atmosphere could be saline mist from the sea, rains or dew formation (CHEN, 2005). Rain can reduce corrosion because it washes possibly corrosive foreign contaminants from the metallic surface. On the other hand, rain can facilitate corrosion by keeping the metallic surface wet or by washing away anticorrosive products that offer protection (JEAN, 1986; ASHED, 1992). It is unlikely that dew formation cleans metallic surfaces considerably, and therefore it is more likely that it increases corrosion (DAVALOS, 1991; DAVALOS, 1991 A). Among the contaminants, sulfur oxides, more particularly sulfur dioxide, have a great influence on the atmospheric corrosion of steel. The two main sources of sulfur dioxide in the atmosphere are the atmospheric oxidation of hydrogen sulfide produced by the decomposition of organic compounds, and the burning of fuels that contain sulfur (GANCEDO, 1980; MARCO, 1990). Sulfur dioxide acts as a catalyst for the corrosion of ferrous metals (UJIHIRA, 1986). Nitrogen compounds in the atmosphere - such as ammonia - also originate from natural sources such as those formed due to the growing use of artificial fertilizers. It can be observed that there are many variables affecting the corrosion speed of steel exposed to the atmosphere. Steel manufacturing processes, including thermal treatment, do not have relevant influence on steel performance in relation to the atmosphere. The most important factors for determining behavior in terms of atmospheric corrosion are the chemical composition of the steel and the kind of microclimate to which the metal has been exposed (MA, 2010). In Hiller's graph (Figure 1) a scheme for the evolution of iron corrosion is proposed, where the initial phase the lepidocrocite $(\alpha-\mathrm{FeOOH})$, and according to the environment where the corrosion occurs, it can follow two paths: the magnetite $\left(\mathrm{Fe}_{3} \mathrm{O}_{4}\right)$, followed by maghemite $\left(\alpha-\mathrm{Fe}_{2} \mathrm{O}_{3}\right)$ and finally evolving to hematite $\left(\alpha-\mathrm{Fe}_{2} \mathrm{O}_{3}\right)$, or the goethite $(\alpha-\mathrm{FeOOH})$ evolving directly to hematite $\left(\alpha-\mathrm{Fe}_{2} \mathrm{O}_{3}\right)$ (BORGES, 1997; HILLER, 1966; XIAO, 2008). The objective of this research was to study the aggressiveness of the atmosphere according to the different polluting agents available in different regions by following the possible variations in the decomposition of steel in each environment.

\section{MATERIAL AND METHODS}

In this study, SAE 1020 steel samples were used $(0.20 \% \mathrm{C}$, from $0.30 \%$ to $0.60 \% \mathrm{Mn}, 0.05 \%$ $\mathrm{Si})$ in the shape of plates with sizes ( $100 \times 150 \times 4)$ $\mathrm{mm}$. This steel was chosen because it is a material that is used constantly in metallic structures. The samples were polished with different granularities $(60,100,180,360)$ mesh of sandpaper made of aluminum oxide. Three points were selected for the exposure of the surfaces, one in an industrial

Figure 1 - Hiller's scheme (HILLER, 1966)

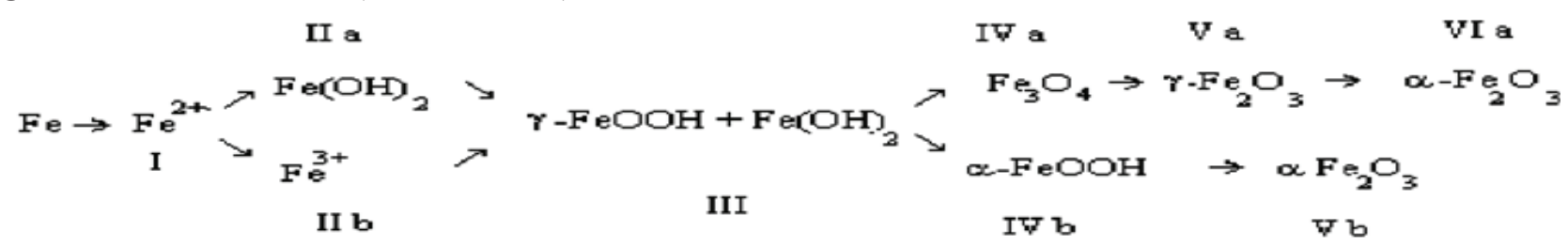

Publ. UEPG Exact Earth Sci., Agr. Sci. Eng., Ponta Grossa, 16 (2): 75-80, dez. 2010 
environment, another in an urban environment, and a third one in a rural environment. All sites were located in the city of Ponta Grossa, in the South of Brazil. One sample was put into a container with distilled water to obtain a pilot corrosion in a controlled environment. The products of corrosion in the samples were collected after 60 and 120 days of exposure by grating with 100 mesh sandpaper. Rainfall was controlled, by a pluviometer in every site of sample exposure. The structural and hyperfine characterizations of samples were obtained by X-ray diffraction, with a cobalt source in Bragg-Brentano geometry, and through Mössbauer spectroscopy, in the transmission mode at room temperature with a source of ${ }^{57} \mathrm{Co}(\mathrm{Rh})$.

\section{RESULTS AND DISCUSSION}

Figure 2 shows the X-ray diffraction results for the corrosion products of samples with 60 days of environmental exposure. The diffractograms respective to the industrial (2.a) and urban (2.b) environments revealed, intense iron peaks (JCPDS 87-0722) as well as the presence of lepidocrocite in a smaller fraction (JCPDS 76-2301).

Figure 2 - X-ray diffractograms for the corrosion products after 60 days.

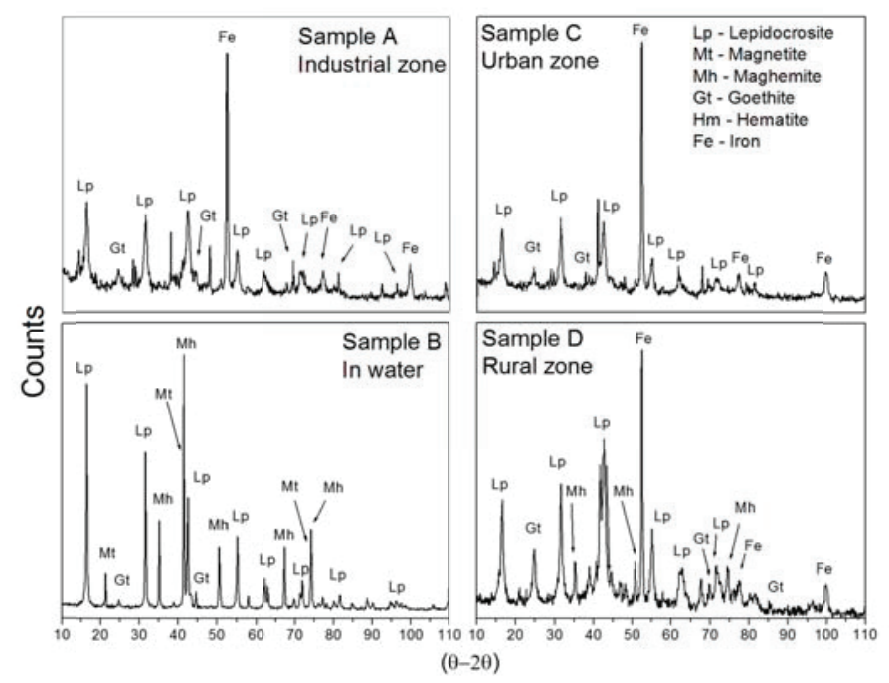

This demonstrates that these environments were not very aggressive during the period of study. Diversely, the lepidocrocite phase was much more evident for the sample exposed to the rural environment (2.c) and clearly a major contribution in the sample was from corrosion in the aqueous environment (2.d). These last two samples also showed the occurrence of goethite (JCDPS 810464). However, only the aqueous environment provided the formation of magnetite (JCPDS 880315) and maghemite (JCPDS 39-1346) phases, (see stages IV.a and V.a in Hiller's scheme, fig.1). This revealed a greater evolution in the corrosion process characterizing this medium, as expected, as the most aggressive during the period of exposure. The iron remaining in the samples (except for the sample kept in water) may be attributed to the gratings of the corrosion products when particles of metallic iron were withdrawn from the steel plates.

Figure 3 - Mössbauer spectra for the corrosion products after 60 days, with the subspectral components.

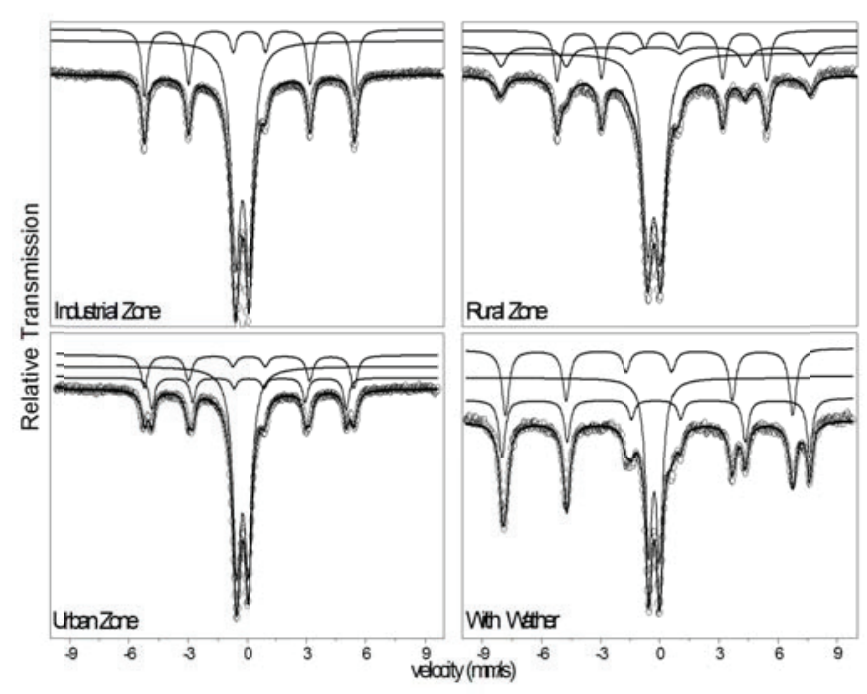

Figure 3 shows the Mössbauer spectra for the same earlier samples. The hyperfine parameters that were obtained, including those for samples with 120 days of environmental exposure, are presented in Table 1. In agreement with the X-ray diffraction results, the samples exposed to the urban and industrial environments revealed metallic iron presence represented by a strong magnetic component (i.e., a sextet with a hyperfine magnetic field of $330 \mathrm{kOe})$. The metallic iron pattern was also observed in the rural sample spectrum, although in a smaller fraction and with enlarged linewidths. The doublet present in all spectra, as expected from the diffractometry analyses, had hyperfine parameters 
consistent with those reported for the lepidocrocite phase. However, this paramagnetic component may have superimposed minor contributions from superparamagnetic iron oxides of very small or very poorly crystallized particles. This could explain why the magnetic pattern for goethite $\left(\mathrm{B}_{\mathrm{hf}}>360\right.$ $\mathrm{kOe}$ ) was not clearly observed in the spectra of the samples from the rural and water environment although its presence was revealed in the respective diffractograms. Because of the predictable similarity between the hyperfine parameters of the (super) paramagnetic oxide phases in soils, it was not reliable to fit the whole quadrupolar contribution using two or more discrete doublets. It is also worthy of note that the doublet subspectral area in each of the two last spectra (see Table 1) also represented the main contribution as revealed by the corresponding phase (i.e., lepidocrocite) in the respective $\mathrm{X}$-ray diffractograms (2c and $2 \mathrm{~d})$. A very weak magnetic component, possibly composed of two subcomponents, could still be seen in the spectrum of the rural sample and was attributed to the initial formation of magnetite and/or maghemite. Again, the small grain size may explain why these phases were not seen in the respective diffractogram. On the other hand, the sample from corrosion in water definitely did not show the iron pattern, but it was possible to identify three other sextets that may be attributed to the magnetite and maghemite phases. The pair of sextets with the smallest hyperfine magnetic fields corresponded to sites A and B of the spinel phase. Again, these contributions were in qualitative consistency with the X-ray results and with previously reported Mössbauer data. The $\mathrm{X}$-ray diffraction results for the corrosion products collected at 120 days are shown in Figure 4.

As before, metallic iron was promptly identified in the samples corroded in the industrial, urban and rural zones. It can also be verified that lepidocrocite was more defined than in the samples collected at 60 days and that small amounts of goethite were found in all samples. This basically corroborates that the longer the time of environmental exposure the greater the corrosion process. In this sense, a longer exposure also caused the appearance of maghemite in the rural sample. For the sample placed in water (4b) there was again maghemite and also magnetite, showing that the chemical nature of phases formed by corrosion did
Figure 4 - X-ray diffractograms for the corrosion products after 120 days.

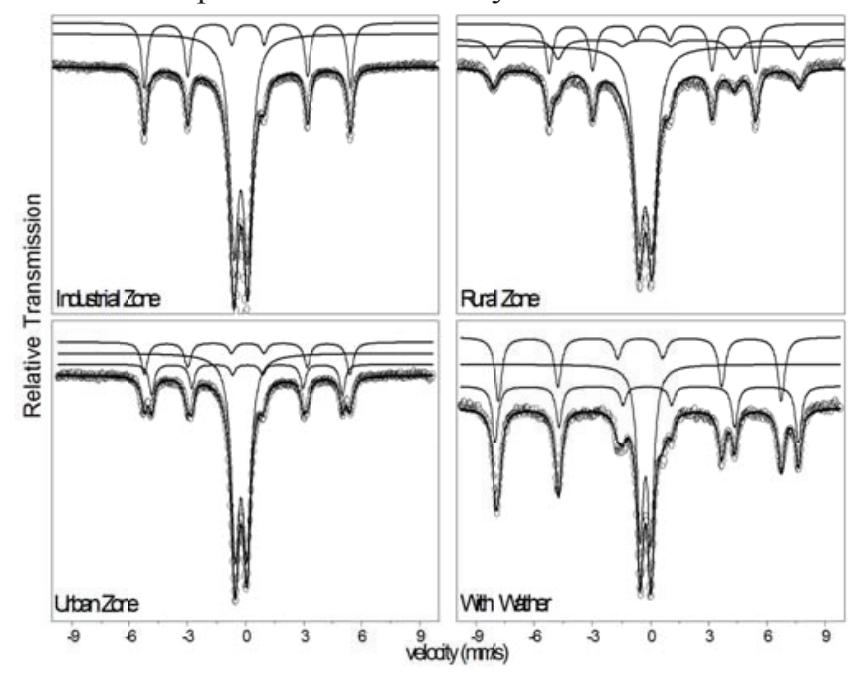

not change with the time during which the steel plate was immersed in that medium. Figure 5 shows the Mössbauer spectra for the samples exposed to the different environments for the longest period. All showed the presence of lepidocrocite and, except for the spectrum of the sample immersed in water, of metallic iron.

Figure 5 - Mössbauer spectra for the corrosion products after 120 days, with the subspectral components.

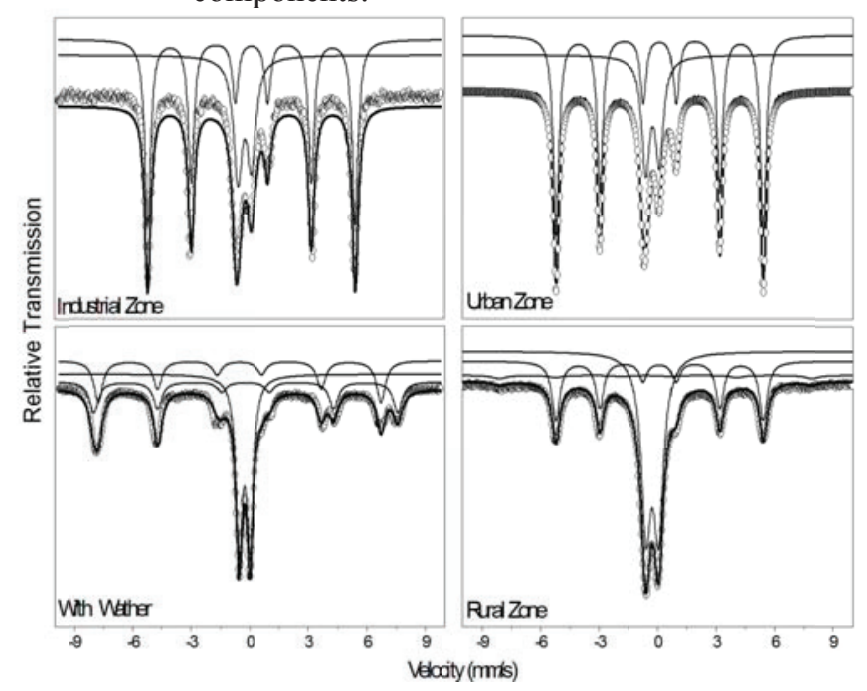

The spectrum for the sample exposed to the rural environment additionally showed the presence of a sextet that, as anticipated by the X-ray results, could be attributed to maghemite. Once more, this characterized the greater environmental aggressiveness in the rural region during the period studied. This result was unexpected because the 
industrial and urban environments are supposed be the most aggressive. It could be related to the relative humidity of the rural region and, more probably, to the strong presence of inorganic agricultural fertilizers in the air. It is unlikely that dew formation considerably cleans the metallic surfaces from particulate material and, therefore, it is more likely that it increases corrosion. Finally, the spectrum of the sample taken from water revealed the well-defined presence of magnetite and maghemite, again in line with the X-ray diffraction results.

\section{CONCLUSIONS}

Differences were observed in the evolution of corrosion products for the different environments where the steel samples were exposed. After 60 days of exposure, all samples showed the presence of lepidocrocite but only that from the rural zone had goethite. With more an equal period, all samples developed goethite but only the sample corroded in the rural zone revealed the presence of maghemite and magnetite. Thus, according to the Hiller model, the rural zone was revealed to be the most aggressive environment, followed by the urban neighborhood and the industrial zone. This result could be related to the greater humidity in the rural zone and to the presence of airborne residues of agricultural fertilizers, or due to agricultural practice, plantil direct, in force in the region, because this practice requires quantities of herbicides and pesticides greater than those used conventionally. Finally, it is relevant to be mention that there is no other study of environmental pollution in this region.

Table 1 - Mössbauer hyperfine parameters and subspectral areas for the corrosion products

\begin{tabular}{|c|c|c|c|c|c|c|c|c|}
\hline Environment & $\begin{array}{c}\text { Time of Exposure } \\
\text { (days) }\end{array}$ & \multicolumn{2}{|c|}{ Phase/ Site } & $\begin{array}{c}\mathrm{IS}^{\mathrm{a}} \\
(\mathrm{mm} / \mathrm{s})\end{array}$ & $\begin{array}{c}\mathrm{QS} \\
(\mathrm{mm} / \mathrm{s})\end{array}$ & $\mathrm{B}_{\mathrm{hf}}(\mathrm{T})$ & $\begin{array}{c}\Gamma \\
(\mathrm{mm} / \mathrm{s})\end{array}$ & $\begin{array}{c}\text { Area } \\
(\%)\end{array}$ \\
\hline \multirow{4}{*}{ Industrial } & \multirow{2}{*}{60} & \multicolumn{2}{|c|}{ Lepidocrocite } & 0.38 & 0.64 & - & 0.67 & 31.0 \\
\hline & & \multicolumn{2}{|c|}{$\alpha-\mathrm{Fe}$} & - & - & 33.2 & 0.36 & 69.0 \\
\hline & \multirow{2}{*}{120} & \multicolumn{2}{|c|}{ Lepidocrocite } & 0.36 & 0.62 & - & 0.51 & 68.4 \\
\hline & & \multicolumn{2}{|c|}{$\alpha-\mathrm{Fe}$} & - & - & 33.0 & 0.34 & 31.6 \\
\hline \multirow{4}{*}{ Urban } & \multirow{2}{*}{60} & \multicolumn{2}{|c|}{ Lepidocrocite } & 0.35 & 0.62 & - & 0.60 & 27.0 \\
\hline & & \multicolumn{2}{|c|}{$\alpha-\mathrm{Fe}$} & - & - & 32.8 & 0.35 & 73.0 \\
\hline & \multirow{2}{*}{120} & \multicolumn{2}{|c|}{ Lepidocrocite } & 0.36 & 0.61 & - & 0.49 & $65.7 ?$ \\
\hline & & \multicolumn{2}{|c|}{$\alpha-\mathrm{Fe}$} & - & - & 32.3 & 0.28 & $14.6 ?$ \\
\hline \multirow{6}{*}{ Rural } & \multirow{3}{*}{60} & \multicolumn{2}{|c|}{ Lepidocrocite } & 0.37 & 0.64 & - & 0.60 & 61.1 \\
\hline & & \multicolumn{2}{|c|}{$\alpha-\mathrm{Fe}$} & - & - & 32.9 & 0.50 & 37.1 \\
\hline & & \multicolumn{2}{|c|}{ Maghemite/Magnetite } & 0.24 & 0.03 & 48.2 & 0.48 & 1.8 \\
\hline & \multirow{3}{*}{120} & \multicolumn{2}{|c|}{ Lepidocrocite } & 0.37 & 0.66 & - & 0.61 & 60.7 \\
\hline & & \multicolumn{2}{|c|}{$\alpha-\mathrm{Fe}$} & - & - & 32.8 & 0.43 & 27.0 \\
\hline & & \multicolumn{2}{|c|}{ Maghemite/Magnetite } & 0.30 & 0.03 & 48.6 & 0.50 & 12.3 \\
\hline \multirow{8}{*}{ Water } & \multirow{4}{*}{60} & \multicolumn{2}{|c|}{ Lepidocrocite } & 0.39 & 0.57 & - & 0.41 & 45.4 \\
\hline & & \multicolumn{2}{|c|}{ Maghemite } & 0.26 & -0.03 & 49.5 & 0.31 & 9.8 \\
\hline & & \multirow{2}{*}{ Magnetite } & Site A & 0.39 & -0.04 & 47.8 & 0.50 & 14.9 \\
\hline & & & Site B & 0.66 & 0.02 & 45.8 & 0.61 & 29.9 \\
\hline & \multirow{4}{*}{120} & \multicolumn{2}{|c|}{ Lepidocrocite } & 0.37 & 0.56 & - & 0.41 & 40.9 \\
\hline & & \multicolumn{2}{|c|}{ Maghemite } & 0.34 & 0.00 & 50.0 & 0.28 & 6.0 \\
\hline & & \multirow{2}{*}{ Magnetite } & Site A & 0.28 & 0.01 & 49.0 & 0.28 & 17.7 \\
\hline & & & Site B & 0.65 & 0.00 & 45.8 & 0.42 & 35.4 \\
\hline
\end{tabular}




\section{ACKNOWLEDGEMENTS}

This work was supported by the Brazilian agency $\mathrm{CNPq}$

\section{REFERENCES}

ASHED, M.; BUTT, M. M.; SIDDIQUE, M.; ANWARUL-ISLAM, M., J. Radioanal. Nucl. Chem., v.165, n.2, p.107, 1992.

BORGES, J. F. M.; COSTA JR, M. I.; LOCATELLI, F.; MOLOSSI,F.A.;FELDMANN,G.;TOUKHVATOULLINE, R.; MUENCHEN, R. J.; ENGLERT, G. E. Hyperfine Interactions, v. 2, p. 149, 1997.

CHEN, Y. Y., TZENG H. J., WEI, L. I., SHIH, H. C., Mater. Sci. and Eng., v.398,

p.47, 2005.

DAVAlos, J., MARCO, J. F., GARCIA, M. et al., Hyp. Interact., v.66, p.63, 1991.

\section{p.871, 1991.} .; et al. Hyp. Interact. v.69,

GANCEDO,J. R.; MARTINEZ, L. M. Proc. NATO Adv. Study Instr. Ser. 61, p.371, 1980.

HILLER, J. E. Werkstoffe und Korrosion, v.11, p.943, 1966.

JEAN, J. A.; FERNANDEZ, B., Eletrochim. Acta, v.34, n.6, p.885, 1986.

MA, Y.; LI, Y.; WANG, F., Coor, Sci, 52, p.1796, 2010.

MARCO, J. F., DAVALOS, J.; GARCIA, M. et al. Hyp. Interact., v.57, p.1991, 1990.

OH, S. J.; COOK, D. C.; TONSEND, H. E. Corr, Sci. v.41, p.1687, 1999.

TAHARA, A.; SHINOHARA, T. Coor, Sci, v.47, p.2589, 2005.

UJIHIRA, Y.; HANDA, A.; FUJINAMI, M. Proc. Ind. Appl. Mössbauer Effect,

p.315, 1986.

XIAO, K.; DONG, C.; LI, X.; WANG, F., Jour. Iron and Steel Res., v.15, p.42, 2008. 